Abstracta Iranica Iranica

Revue bibliographique pour le domaine irano-aryen

Volume 25 | 2004

Comptes rendus des publications de 2002

\title{
The Splendour of Iran. London, Booth-Clibborn, 2001,
} 3 vol.

Bernard Hourcade

\section{OpenEdition}

1 Journals

Édition électronique

URL : http://journals.openedition.org/abstractairanica/4062

DOI : 10.4000/abstractairanica.4062

ISSN : 1961-960X

\section{Éditeur :}

CNRS (UMR 7528 Mondes iraniens et indiens), Éditions de l'IFRI

\section{Édition imprimée}

Date de publication : 15 mai 2004

ISSN : 0240-8910

\section{Référence électronique}

Bernard Hourcade, «The Splendour of Iran. London, Booth-Clibborn, 2001, 3 vol. », Abstracta Iranica [En ligne], Volume 25 | 2004, document 20, mis en ligne le 15 mars 2006, consulté le 25 septembre 2020. URL : http://journals.openedition.org/abstractairanica/4062 ; DOI : https://doi.org/10.4000/ abstractairanica.4062

Ce document a été généré automatiquement le 25 septembre 2020.

Tous droits réservés 


\title{
The Splendour of Iran. London, Booth- Clibborn, 2001, 3 vol.
}

\author{
Bernard Hourcade
}

1 Renouant avec la tradition des beaux livres, cette publication magnifiquement illustrée par les photographies de J. Ghazbanpour, présente un tableau d'ensemble de l'histoire artistique et culturelle de l'Iran. C'est une œuvre considérable, par sa qualité technique, mais surtout par la volonté de N. Pourjavady de s'entourer des meilleurs spécialistes iraniens mais aussi étrangers pour rédiger les divers chapitres, afin que le contenu scientifique de l'ensemble soit incontestable et apporte des informations et analyses de nature à faire de ce livre sur les splendeurs de l'Iran une publication à la fois savante et belle. Chaque volume comprend un index, une bibliographie, un glossaire. La qualité et l'abondance des illustrations (photos d'Iran ou objets de divers musées internationaux) est tout a fait exceptionnelle; jamais depuis A. Pope, on n'avait réuni une telle somme sur les arts iraniens.

2 Le premier volume dirigé par A. Sh. Shahbazi est consacré à l'antiquité : les céramiques, sculptures, sceaux, monuments, poteries, textiles ou métaux de la préhistoire aux Sassanides sont présentés principalement par des spécialistes iraniens (Y. Majidzadeh, M. Azarnoush, S. Malek-Shahmirzadi...).

3 Le second volume est consacré à l'architecture et à l'urbanisme de la période islamique. Coordonné par C. Parham, ce livre présente les caravansérails, ponts, barrages, places, mosquées, madrasas, minarets, bazars, palais, maisons, jardins et éléments de la décoration des bâtiments. Parmi les nombreux collaborateurs, on peut citer M. Kiani, P. Varjavand, H. Lâleh, R. Hillenbrand, et M. Haeri. Les œuvres présentées vont des débuts de l'islam à la période Qajar, mais n'abordent pas la période moderne et contemporaine.

4 Le troisième volume également dirigé par C. Parham, traite des arts décoratifs de la période islamique (livre, peinture, tapis, verre, céramique) et se termine par la présentation du continuum culturel de l'Iran avec notamment la présentation des cultures populaires par S. Shahshahani. 
5 Ces trois magnifiques volumes sont donc un plaisir pour l'œil et une présentation presque exhaustive et savante des multiples facettes des arts de l'Iran des origines à l'aube $\mathrm{du} 20^{\mathrm{e}} \mathrm{s}$. On regrettera cependant que la période contemporaine ne soit qu'esquissée. Un quatrième volume sur les arts et les cultures de l'Iran d'aujourd'hui serait donc le bienvenu et trouverait sa place en s'inscrivant dans le splendide héritage présenté ici.

INDEX

Thèmes : 1.3. Ouvrages généraux, histoire de la discipline

\section{AUTEURS}

BERNARD HOURCADE

CNRS - Paris 